Volume 7

Number 1 Spring 2016 (Special Issue)

Article 4

4-11-2016

\title{
The Interwoven Evolution of the Early Keyboard and Baroque Culture
}

Rachel Stevenson

Cedarville University, rastevenson@cedarville.edu

Follow this and additional works at: https://digitalcommons.cedarville.edu/musicalofferings

Part of the Ethnomusicology Commons, Fine Arts Commons, Musicology Commons, Music Performance Commons, and the Music Theory Commons

DigitalCommons@Cedarville provides a publication platform for fully open access journals, which means that all articles are available on the Internet to all users immediately upon publication. However, the opinions and sentiments expressed by the authors of articles published in our journals do not necessarily indicate the endorsement or reflect the views of DigitalCommons@Cedarville, the Centennial Library, or Cedarville University and its employees. The authors are solely responsible for the content of their work. Please address questions to dc@cedarville.edu.

\section{Recommended Citation}

Stevenson, Rachel (2016) "The Interwoven Evolution of the Early Keyboard and Baroque Culture," Musical Offerings: Vol. 7 : No. 1 , Article 4.

DOI: 10.15385/jmo.2016.7.1.4

Available at: https://digitalcommons.cedarville.edu/musicalofferings/vol7/iss1/4 


\title{
The Interwoven Evolution of the Early Keyboard and Baroque Culture
}

\section{Document Type}

Article

\begin{abstract}
The purpose of this paper is to analyze the impact that Baroque society had in the development of the early keyboard. While the main timeframe is Baroque, a few references are made to the late Medieval Period in determining the reason for the keyboard to more prominently emerge in the musical scene. As Baroque society develops and new genres are formed, different keyboard instruments serve vital roles unique to their construction. These new roles also affect the way music was written for the keyboard as well. Advantages and disadvantages of each instrument are discussed, providing an analysis of what would have been either accepted or rejected by Baroque culture. While music is the main focus, other fine arts are mentioned, including architecture, poetry, politics, and others. My research includes primary and secondary resources retrieved from databases provided by Cedarville University. By demonstrating the relationship between Baroque society and early keyboard development, roles and music, this will be a helpful source in furthering the pianist's understanding of the instrument he or she plays. It also serves pedagogical purposes in its analysis of context in helping a student interpret a piece written during this time period with these early keyboard instruments.
\end{abstract}

\section{Keywords}

Keyboard, Baroque, clavichord, harpsichord, pianoforte, spinet

\section{Creative Commons License}

\section{(c) (i) $\ominus$}

This work is licensed under a Creative Commons Attribution-Noncommercial-No Derivative Works 4.0 License. 


\title{
The Interwoven Evolution of the Early Keyboard and Baroque Culture
}

\author{
Rachel Stevenson \\ Cedarville University
}

卫

ranslated from the Portuguese barroco, or "misshapen pearl," the Baroque Era is famous for its emphasis on elaborate, overdone decoration. ${ }^{1}$ Following a less dramatic Renaissance Period, Europe experienced a shift of focus to theatrics and embellished extravagance. Several examples of this shift can be portrayed through art, architecture, poetry, as well as the music of the Baroque. Shakespeare's plays reached new heights of drama; architecture and art became a means to exemplify one's own talent and virtuosity, and music began to employ the growing fascination for the solo performer and the observing audience. ${ }^{2}$ Opera, instrumental music, and other forms of professional performance seemed to take over the stage, no longer stressing audience participation, but instead viewing the audience as mere observers meant to passively watch and be moved by the performer(s). Music and art came to be enjoyed not only for its ability to serve other functions, but simply for the sake of enjoying the art itself. New genres and other ideas were born, including an emphasis on improvisation, dissonance, rhythmic drive, and an increasingly evolving role of the instruments; in other words, more "barroco."

One role for instruments was the basso continuo, or "continuous bass," which was a general written out bass line that set a guideline for the performer when improvising that line. The concept of the independent but equally important bass and treble lines became essential as well. A crucial instrument to employ this was the keyboard, which played a

\footnotetext{
${ }^{1}$ Nolan Gasser, "Period: Baroque," Classical Archives, 2015, accessed October 12, 2015, http://www.classicalarchives.com/period/4.html.

${ }^{2}$ Eric Cochrane, "The Transition from Renaissance to Baroque: The Case of Italian Historiography," History and Theory 19, no. 1 (1980): 21-38, doi: $10.2307 / 2504811$.
}

Musical Offerings, vol. 7, no. 1, pp. 43-53.

ISSN 2330-8206 (print); ISSN 2167-3799 (online);

(C) 2016, Rachel Stevenson, licensed under CC BY-NC-ND

(http://creativecommons.org/licenses/by-nc-nd/3.0/) 
vital role in the musical culture of the Baroque Era, and would become one of the most prominent and instruments to develop in history. The early keyboard developed with the cultural shifts of the Baroque Era, resulting in an advancing keyboard instrument. Because of the progression of the keyboard, the music written for it evolved, as well as the roles it played in Baroque musical society.

As previously mentioned, the keyboard emerged as one of the most prominent instruments of its time and in history altogether. Several reasons for this new appeal for a keyboard instrument were the developing genres and concepts of the Baroque Era. ${ }^{3}$ New genres included the concerto, early sonata, and vocal pieces using keyboard accompaniment. Also part of this demand for a keyboard instrument was a rising interest in instrumental music as well as the popularity of contrapuntal textures in music. The late Renaissance began this new emphasis on the importance of instruments, while also continuing the concept of early polyphony. One instrument that could satisfy both of these cultural demands was the keyboard, which could play multiple lines at once using the right hand and left hand. This created a variety of textures both in a solo setting, as well as in ensemble work.

Some of these keyboard instruments that were used included the eschiquier, organ, clavichord, harpsichord, virginal, spinet, and the early pianoforte. Each of these played a slightly different role, dependent on the mechanics used to construct each instrument. Some proved more successful, staying relevant through the test of time and continuing the greater evolution towards the modern piano than others. Other than the organ, each of these early keyboards produced sound using strings. Set apart in the realm of keyboards, therefore, is the organ, producing its sound uniquely through pipes. ${ }^{4}$

The organ holds a very significant place in the discourse of not only keyboards, but in the realm of instrumental history as well. Known as the "king of instruments" due to its versatility and fullness in sound, the organ's initial entrance into society can be traced as far back as the

\footnotetext{
${ }^{3}$ Ibid., 22.

${ }^{4}$ David Verotta, "Short History of the Pianoforte," Musica, accessed October 13, 2015, http://www.davideverotta.com/A_folders/Teaching/historypiano.html.
} 
sixth century B.C. in the form of a panpipe instrument. ${ }^{5}$ Gradually this instrument was modified until the modern organ was born. Used mostly in sacred settings, the organ, like the other keyboard instruments, could be sounded through the pressing of keys, but contained pipes rather than strings. Pipes can be created with varying methods, thus capable of contrasting timbres of sound. The more pipes an organ contains, the wider variety and fullness of sound that can be created. The length of pipe also determines pitch, so the number of keys it contains determines the number of pipes. When the key is pressed down, the connected action signals the wind from the pipes to rush through its subsequent pipe, thus creating sound. The action then must signal the stop so that the connected pipes above that note do not sound. An early form of the pedal was present, able to hold out a drone sound that was popular during the Renaissance and Baroque.

Due to its rich and full cathedral sound, the organ gradually became one of the most used instruments of its time. Able to create polyphony while holding out a pedal point in the bass, it became extensively used mostly in church settings and was popular for Baroque listeners due to its ability for this polyphony. During the Protestant Reformation, church leaders such as Martin Luther cherished the chorale, a vocal work that could easily be transcribed for the organ because of its capabilities with versatile voices in its variation of pipes. Also used in Mass Settings, the organ could be used either soloistically or in alternation with choir chants. In this Renaissance and early Baroque culture especially evident is the presence of the church in society. Because of its unique sound, the organ seemed most fitting in the church, not being as versatile for secular genres. Though the church exhibited less flashy barroco characteristics than secular settings of the culture, some styles overlapped. Polyphony was the dominant texture of both, with similar dissonance and consonance to evoke emotional expressivity. The organ as a keyboard instrument fit these demands in its full polyphonic and harmonic capabilities, as were the early stringed keyboards.

Perhaps the earliest known stringed keyboard to exist was the eschiquier, a sparsely documented keyboard ancestor. Known to be a "primitive clavichord," the eschiquier was a keyboard instrument

\footnotetext{
${ }^{5}$ Lynn Trapp, "The Organ through the Ages: A Versatile Instrument," Pastoral Music 38, no. 5 (Sept. 2014): 13, Publisher Provided Full Text Searching File, EBSCOhost.
} 
cryptic in nature, whose mystery centers in its low quantity of definitive evidence. ${ }^{6}$ Mentioned in early manuscripts but rarely described in clarity, it can date back even to the fourteenth century in London. French for "chess board," one of the very few references to the eschiquier dates back to a letter between King John I of Aragon and the Duke of Burgundy written in 1388. In it, King John I requests for the Duke's minstrel to play this instrument which he described as similar to the organ except sounded by strings rather than pipes. ${ }^{7}$ Because of the lack of written substantiation for this instrument, it is not given a significant rank in the discourse of keyboard instruments in music history.

It is, however, understood to be the bridge to more progressive keyboards for future development. The role it played in society may not have been as significant as what the keyboards played in Baroque society, but it served a function nonetheless. During the late Medieval Period, music for the sake of simple enjoyment was less common for the middle class audience, but instead served its purpose mostly in the church or courts only. This seems to be one function of the eschiquier. The King of England and Duke of Burgundy were of royalty, requiring the service of those who were able to play this instrument for the entertainment of the courts. Later music would be enjoyed for the common people, being enjoyed for the music itself.

One of the first revolutionary stringed keyboards, the clavichord was a very quiet instrument due to its construction. Smaller in size, the clavichord produced sound in a different manner than its relative, the harpsichord. When a key was pressed down, it lifted a small copper square called a tangent, which would strike the string and lift a damper, causing the strings to vibrate and the sound to be heard for only as long as the key was pressed down. Considered to be the most similar early ancestor to the piano, this instrument was unable to produce much sound. Being much smaller in size than the modern piano, it contained

\footnotetext{
${ }^{6}$ Fenella Saunders, "They Invented It When?" Discover October 1, 2001, http://discovermagazine.com/2000/oct.

${ }^{7}$ John Gillespie, "Stringed Keyboard Instruments: Their Origins and Development," in Five Centuries of Keyboard Music (Belmont, CA: Wadsworth Publishing Company, 1972), 3.
} 
a maximum of two strings per key, unlike the much larger grand piano, which has up to three strings each key. ${ }^{8}$

Regardless of its size and soft volume, the clavichord was popular during this era for multiple reasons. Due to its smaller size, this keyboard instrument was more suitable to exist in homes during the Baroque Era. Several composers, including Johann Sebastian Bach, were known to contain this smaller keyboard instrument in their houses. Perhaps the best use for the early clavichord was either solo performance or accompaniment for a single vocalist. ${ }^{9}$ The clavichord emerged successfully during this era that stressed emotional expression. Theories such as the Doctrine of Affections concluded that spectators could be moved aurally or visually through the means of the artist. Visually, this included colors, while music was written to stir emotional responses through the use of consonance and dissonance, as well as continuing the theme of drama through counterpoint and thick textures. Instruments such as the clavichord were capable of creating a variety of colors and extravagance through counterpoint. It soared as an important instrument amongst the emphasis on the solo instrument. The clavichord, being a keyboard instrument, was versatile in its ability to play multiple notes at once, thus capable of counterpoint and chordal composition. Playing chordally could move the emotions through thirds and sixths, as well as resolving dissonance. It could trill, thus participating in the dramatic ornamentation that Baroque members craved, while also being an attainable instrument in homes because of its small size.

Another prominent uniqueness of the clavichord is its ability to produce a variety of volume, known as dynamics. Like the modern piano, the clavichord's sound was created from the striking of a string, rather than plucking as in the harpsichord. ${ }^{10}$ The performer could therefore adjust his or her rate of pressing down the keys in order to control the speed of the tangent strike, thus creating crescendos and decrescendos. Of course, these volume adjustments were much slighter than those of its later successors. Yet this ability to create volume was one significant strength of the clavichord.

\footnotetext{
${ }^{8}$ A. J. Hipkins, "The Old Clavier or Keyboard Instruments; Their Use by Composers, and Technique," Proceeding of the Musical Association 47, no. 1 (1885): 139-148, doi:10.1093/jrma/12.1.139.

${ }^{9}$ Francis Knights, "Clavichords and Other Claviers," Early Music 42, no. 2 (2014): 321-323, doi:10.1093/em/cau014.

${ }^{10}$ Verotta, "Short History of the Pianoforte."
} 
The harpsichord was another popular keyboard of the Baroque Era during the escalating role of the keyboard. Famed to be the "concert grand" of the time, it was clear that the harpsichord was a superior keyboard instrument. ${ }^{11}$ Larger in size and sound than the clavichord, the harpsichord was much better suited to play a role in the larger group settings. Though there is evidence of more primitive harpsichords being built as early as the Middle Ages, significant improvements were made so that the instrument is considered to have truly blossomed during the Baroque Era. The Ruckers family in Germany was instrumental in their development of the harpsichord, standardizing the use of four and eight foot registers, as well as stops for controlling the sound. Hans Ruckers was known as the first master builder of the harpsichord as early as 1579 in Antwerp, Germany. His family continued to develop this business and build a legacy that later harpsichord manufacturers would use as a model for their work. ${ }^{12}$

Like the clavichord, the harpsichord creates sound when the key is pressed down, which caused a vibration of strings inside the instrument. Harpsichords typically contain one or two rows of keyboards, called manuals that create the sound. ${ }^{13}$ These manuals controlled the two or three sets of strings that run parallel to the keyboard, which could be tuned to either unison or increased octave. Rather than using a hammer, the harpsichord creates sound with a plectrum, which was a sort of quill that would pluck the strings. The plectrum was attached to a tongue hinged in a wooden piece called a jack that sat upon the back end of the key lever. As a key is pressed down, the lever would lift the jack and cause the quill to pluck the string, while immediately the tongue tilts back and prevents another sounding of the string from the quill by use of a cloth damper.

Because plucking rather than striking the strings creates the sound of the harpsichord, it is nearly impossible to create a variety of volume with this instrument. Gradual dynamics could not be created, but occasionally sudden shifts of terraced dynamics could be played. This remains the key shortcoming of the harpsichord, although it continued to be widely used during the Baroque Era. The harpsichord was one of the only instruments at this time that could not create dynamic

\footnotetext{
${ }^{11}$ Gillespie, 6.

12 Ibid., 7.

${ }^{13}$ Laurence Libin, "Keyboard Instruments," The Metropolitan Museum of Art

Bulletin 47, no. 1 (1989): 1-56, doi:10.2307/3258850.
} 
variation. In contrast to this was the violin, an instrument of weighty importance, rivaling the voice in its capabilities. With the emphasis being on the solo instrument and expressiveness through genres and styles, the harpsichord seemed unfinished in its lack of dynamic expression. Rather than creating shades of color through dynamics, other means were used, such as fluctuating textures and dissonance to create more of an illusion of increased or fading sound. ${ }^{14}$ Thus thicker textures would be perceived as a fuller rather than "louder" sound, and ornamentation served the purpose of what musicians would consider the accent on the modern piano.

Ornamentation on the harpsichord mirrors the Baroque emphasis on exaggerated extravagance. Because dynamics could were unable to noticeably shape a piece, ornaments such as trills, turns, and others must be used to fit the desire of the musicians and listeners. This was a way to create expression, and remains applicable today as pianists strive to accurately interpret the execution of a Baroque piece originally composed for a harpsichord. ${ }^{15}$ Thus the trill was an essential piece of Baroque repertoire, not only for the keyboard but also for other instruments such as the emerging "singing" violin. Though very little dynamics were possible, the harpsichord was an invaluable instrument during the Baroque Period.

The harpsichord mainly functioned as either a basso continuo or for solo repertoire. Being larger and much fuller in volume than other keyboards like the clavichord, the harpsichord was generally used in ensemble settings to be the basso continuo. Like the clavichord, the harpsichord can produce harmonies by pressing down multiple keys at once. This gave it a greater variety, including the ability to realize figured bass, and fill in the sound between the bass and treble notes, as well as the ability to create counterpoint, which was one of the most central features of Baroque music. Another includes figured bass, the written bass line denoted by numbers that the performer was to use as a standard on which to improvise.

Improvisation stands out as one of the most important skills for a keyboardist to possess during the Baroque Era. The embellishments that were popular often were not written out in the music that a

14 Mark Kroll, "Techniques," in Playing the Harpsichord Expressively: A Practical and Historical Guide (Lanham, MD: Scarecrow Press, 2004): 34.

${ }^{15}$ Ibid. 
performer would play. Rather, the performer would use the figured bass as a general guide that must be elaborated on by the artist. This correlates with the Baroque emphasis on the soloist instead of the composer, which would be an idea for later development. Solo repertoire for the harpsichord included the toccata, fantasia, suites, preludes, fugues, and a variety of dance music. Dance music was essential for keyboard solo repertoire, using the rhythms and forms of dances to shape the keyboard dance music. This included suites, a multi-movement dance piece unified often by the key, but with distinct characteristics of rhythm matching the dance for which it corresponds. Perfectly suited for the harpsichord, these genres each required a level of improvisation and virtuosity in order to achieve a sparkling sound capable of smooth embellishments and expressiveness in performance. Church musicians were also expected to improvise.

Besides being a successful solo instrument, the harpsichord was also popular for its ensemble capabilities, especially in accompaniment for opera. The prevailing vocal genre of the this era, opera thrived in its Baroque style of emphasis on the performer through dramatic staging of stories often centered in Greek tragedy or other "larger than life" figures. The audience enjoyed listening to soloist cadenzas, dramatic and often romantically tragic storylines, as well as an importance in the role of the accompanists, which included the harpsichord. Sparkling clarity and an ability to use harmony and figured bass with improvisation for the basso continuo line caused an increased demand for the harpsichord in opera. Yet it blended well with other supporting instruments to create a rich Baroque opera ensemble.

Very similar versions of the harpsichord include the virginal and spinet. The virginal is a smaller, rectangular version of the harpsichord. The preferred instrument in England, it only contained one string per note instead of three or four like its larger relative. In addition to this is the spinet, which was nearly the size of the harpsichord, but had slightly angled rather than parallel strings compared to the keyboard. ${ }^{16}$ These instruments would have been used to play comparable genres as the harpsichord but with a slightly less rich sound. Due to the duller sound of these instruments, they played a much less weighty role in music history. Unable to stand out in a solo setting such as the concerto, the harpsichord proved the most versatile of the existing keyboard instruments.

${ }^{16}$ Gillespie, 9. 
In the latter portion of the Baroque Era, however, a new instrument was conceived. Though overlooked at first, this instrument would soon rise to the top of all keyboard instruments, paving the way for the modern grand piano. The pianoforte, named for its dynamic characteristics, was created in 1709 by Florentine instrument maker Bartolomeo Cristofori. Referring to this instrument as a gravicembalo col piano e forte, or "harpsichord with soft and loud," Cristofori essentially built a larger harpsichord except with hammers. Rather than the string being attacked with the tip of a plectrum, the plectrum was replaced with a hammer and lever that would allow the string to vibrate when struck from a downward motion with the hammer. ${ }^{17}$ The speed of the hammer could be adjusted based on the speed and intensity that a note was pressed down, thus allowing for contrast in volume. The pianoforte also contained a damper pedal pressed with the knee, capable of holding out the sound even beyond pressing the keys. Although still needing some adjustments in the action of the pianoforte, this was a revolutionary instrument not adequately recognized until almost twenty years after it creation.

The pianoforte was not accepted at first due to the noticeable adjustments in playing style. ${ }^{18}$ The keys, being heavier than harpsichord keys, required more force to create sound, but too much force could also damage the strings. Moreover, the articulation was created through the downward motion of the keys rather than the release of keys after pressing them down. In addition to these significant differences includes the fact that Baroque members were very satisfied with the harpsichord as the preeminent keyboard of the time. The lack of dynamics seemed minimal when compared to the difficult adjustment in playing the pianoforte. Nevertheless, a gradual increase of awareness about the instrument would soon uncover the ongoing capabilities it possessed in order to create a beautiful sound appreciated by the latter Classical society. Late Baroque and early Classical composers played a key role in the bridge from the harpsichord to later piano instruments that are used almost exclusively today.

\footnotetext{
${ }^{17}$ Ibid., 10.

${ }^{18}$ Rachel A. Lowrance, "Born to Conquer: The Fortepiano's Revolution of Keyboard Technique and Style," Musical Offerings 5, no. 1, (2014): 1-14, doi:10.15385/jmo.2014.5.1.1.
} 
The Baroque Era experienced a variety in keyboard instruments, each with unique advantages and disadvantages. These keyboards progressed with the Baroque culture and taste in music, providing listeners with the genres and styles they wanted to experience. Members of the Baroque loved drama, ornamentation, and the performer. Keyboards satisfied these needs, able to accompany theatrics, such as the opera seria, while also providing thick textures of counterpoint and satisfying harmonies of the time. Though early keyboards such as the eschiquier, virginal, spinet, and the organ played a role in society, the beginning of the early stringed keyboards mostly featured the clavichord, a small keyboard capable of dynamics but also too small to participate in larger scale genres. A cousin of the clavichord, the harpsichord took over the musical scene due to its larger size and rich, full sound. The harpsichord excelled in its ability as both a solo instrument in genres like the concerto, but also became instrumental in its ensemble works as a basso continuo. Being the most popular instrument of the time, it would, more importantly, be the link to the pianoforte and more advanced keyboards suitable in the society and musical preference of the future.

\section{Bibliography}

Adlam, Derek. "Early Keyboard Music." Early Music 35, no. 1 (2007): 144-46. http://www.jstor.org/stable/4137289.

Chung, David. "Keyboard Music from France and the Low Countries." Early Music 42, no. 1 (2014): 147-50. doi:10.1093/em/cas094.

Cochrane, Eric. "The Transition from Renaissance to Baroque: The Case of Italian Historiography." History and Theory 19, no. 1 (1980): 21-38. doi:10.2307/2504811.

Cyr, Mary. "Origins and Performance of Accompanied Keyboard

Music in France." Musical Times 156, no. 1932 (2015): 7-26.

MasterFILE Premier, EBSCOhost.

Gasser, Nolan. "Period: Baroque." Classical Archives. 2015. Accessed

October 12, 2015.

http://www.classicalarchives.com/period/4.html.

Gillespie, John. "Stringed Keyboard Instruments: Their Origins and

Development." In Five Centuries of Keyboard Music, 3.

Belmont, CA: Wadsworth Publishing Company, 1972. 
Hipkins, A.J. "The Old Clavier or Keyboard Instruments; Their Use by Composers, and Technique." Proceeding of the Musical Association 12, no. 1 (1885): 139-148, doi:10.1093/jrma/12.1.139.

Kevorkian, Tanya. "Town Musicians in German Baroque Society and Culture." German History 30, no. 3 (2012): 350-71. Humanities International Complete, EBSCOhost.

Knights, Francis. "Clavichords and Other Claviers." Early Music 42, no. 2 (2014): 321-323, doi:10.1093/em/cau014.

Kroll, Mark. "Techniques." In Playing the Harpsichord Expressively: A Practical and Historical Guide 1-50. Lanham, MD: Scarecrow Press, 2004.

Latcham, Michael. "Pianos and Harpsichords for Their Majesties." Early Music (2008): 359-396. doi:10.1093/em/can047.

Libin, Laurence. "Keyboard Instruments." The Metropolitan Museum of Art Bulletin 47, no. 1 (1989): 1-56. doi:10.2307/3258850.

Lowrance, Rachel A. "Born to Conquer: The Fortepiano's Revolution of Keyboard Technique and Style." Musical Offerings 5, no. 1 (2014): 1-14. doi:10.15385/jmo.2014.5.1.1.

MacRitchie, Jennifer, and Giulia Nuti. "Using Historical Accounts of Harpsichord Touch to Empirically Investigate the Production and Perception of Dynamics on the 1788 Taskin." Frontiers in Psychology 6, no. 183 (2015): doi:10.3389/fpsyg.2015.00183.

Mobbs, Kenneth. "Stops and Other Special Effects on the Early Piano." Early Music 12, no. 4 (1984): 471-76.

doi:10.1093/earlyj/12.4.471.

Patrizio, Barbieri. "Harpsichords and Spinets in Late Baroque Rome." Early Music 40, no. 1 (2012): 55-72. doi:10.1093/em/cas023.

Saunders, Fenella. "They Invented It When?" Discover October 1, 2001. http://discovermagazine.com/2000/oct.

Sutherland, David. "On the Production of Pianos in Florence 17001750." Early Keyboard Journal 27/28/29 (2012): 47-75. Academic Search Complete, EBSCOhost.

Trapp, Lynn. "The Organ through the Ages: A Versatile Instrument." Pastoral Music 38, no. 5 (September 2014): 13. Publisher Provided Full Text Searching File, EBSCOhost.

Verotta, David. "Short History of the Pianoforte." Musica. Accessed October 13, 2015. http://www.davideverotta.com/A folders/Teaching/historypian o.html. 